\title{
Prevalence of Cardiovascular Risk Factors in relation to Socio-demographic profile of the Life Course Study in Cardiovascular Disease Epidemiology Study (LIFECARE) Philippine Cohort
}

\author{
Felix Eduardo R. Punzalan, 1,2,4 Rody G. Sy 1,2,3 Olivia T. Sison, 2,4,5 \\ Nina T. Castillo-Carandang, ,2,45 Wilbert Allan G. Gumatay, ${ }^{2}$ Paul Ferdinand M. Reganit, $, 1,2$ \\ Paulette D. Nacpil-Dominguez, ${ }^{2}$ Queenie G. Ngalob, ${ }^{2}$ Felicidad V. Velandria ${ }^{2}$ and Elmer Jasper B. Llanes ${ }^{1,2}$ \\ ${ }^{1}$ Department of Medicine, College of Medicine and Philippine General Hospital University of the Philippines Manila \\ ${ }^{2}$ LIFE course study in CARdiovascular disease Epidemiology (LIFECARE) Philippine Study Group, Lipid Research Unit, UP-PGH, Manila, Philippines \\ ${ }^{3}$ Cardinal Santos Medical Center, San Juan City, Metro Manila, Philippines \\ ${ }^{4}$ Department of Clinical Epidemiology, College of Medicine, University of the Philippines Manila \\ Institute of Clinical Epidemiology, National Institutes of Health, University of the Philippines Manila
}

\begin{abstract}
Objective. To describe the distribution of the clinical cardiovascular risk profile of the LIFECARE Philippine cohort in relation to its socio-demographic factors

Methods. We recruited a total of 3,072 apparently healthy participants from Manila and nearby provinces of Rizal, Batangas, Bulacan and Quezon. Face-to-face interview was done to obtain socio-demographic data. Baseline clinical parameters and biochemical tests were obtained. Prevalence of cardiovascular risk factors was determined by sex, place of residence, level of education and employment.
\end{abstract}

Results. Overall prevalence of diabetes mellitus was at $5 \%$, similar between sexes, area class, educational attainment and employment status. More smokers were male, employed or with an elementary level of education. Prevalence of hypertension was at $14.5 \%$ and was seen more in males, urban dwellers, employed or with an elementary level of education. Dyslipidemia was seen more in males, living in the rural areas, employed or with a college level of education. Lastly, obese participants were seen more in females, living in urban areas, employed or with a college level of education.

Conclusion. Older, male and employed participants who are living in the urban areas have more cardiovascular risk factors.

Key Words: cardiovascular risk factors, socio-demographic, LIFECARE

Corresponding author: Felix Eduardo R. Punzalan, MD, MSc Clin Epi Section of Cardiology

Department of Medicine

Philippine General Hospital

University of the Philippines Manila

Taft Avenue, Ermita, Manila 1000 Philippines

Telephone: +6325548400 local 3670

Email: docyp2@yahoo.com

\section{Introduction}

For more than a decade, cardiovascular disease (CVD) remains to be the leading cause of mortality in the Philippines. ${ }^{1}$ Pioneers in the study of CVD epidemiology perceived the idea that CVD is not an inevitable result of aging but rather due to factors that are related to the environment and change in lifestyle. CVD is a continuum that starts from a chain of events initiated by numerous risk factors such as cigarette smoking, diabetes mellitus, elevated cholesterol, diabetes mellitus, obesity and physical inactivity. These cardiovascular risk factors promote oxidative stress and enhance cellular adhesion molecules, which lead to endothelial dysfunction and progression of disease. However, these events do not happen in a sequential manner but may overlap and interconnect with each other. ${ }^{2}$ Early identification of these risk factors and addressing treatment, whether pharmacologic or nonpharmacologic, retard the cascade of events that lead to CVD.

Since 1998, the National Nutrition and Health Survey (NNHeS) has been conducting a study every five years to look at the prevalence of cardiovascular disease and its risk factors. ${ }^{3,4,5}$. In the latest survey of 2008, the prevalence of cigarette smoking was $31 \%$, diabetes mellitus by fasting blood glucose $3.9 \%$, dyslipidemia $72 \%$, hypertension $20.6 \%$, obesity by body mass index (BMI) $4.9 \%$, and obesity by waist:hip ratio $10.2 \%$ and $65.6 \%$ in males and females, respectively. ${ }^{5}$ To date, the $\mathrm{NNHeS}$ is the only recognized prevalence data of CVD and its risk factors in the Philippines.

It has been a known fact for years that those living in the third world countries are observed to have poorer health outcomes. In the Philippines, access to quality medical care is limited for those who are indigent since the patient shoulders most of the expenses. There are numerous of evidences that show an inverse relationship between socioeconomic status and CVD risk factors. ${ }^{6-10}$ The aim of this 
paper is to look into the prevalence of CVD risk factors in relation to socio-demographic profile among the participants of the Life Course Study in Cardiovascular Disease Epidemiology (LIFECARE) cohort study.

\section{Objectives}

\section{General Objective}

To describe the distribution of the clinical cardiovascular risk profile of the LIFECARE Philippine cohort in relation to its socio-demographic factors

\section{Specific Objective}

To describe the prevalence of clinical cardiovascular risk profile of the LIFECARE Philippine cohort in relation to sex, place of residence, educational attainment and employment status

\section{Materials and Methods}

\section{Study Population}

LIFECARE is a descriptive, prospective cohort study, which included apparently healthy individuals aged 20 to 50 years old. Recruitment of participants was done from the year 2009 to 2011. Certain provinces and barangays from Luzon namely, Metro Manila, Rizal, Batangas, Bulacan and Quezon were conveniently chosen based on proximity and safety. Excluded were those who have existing cardiovascular disease as determined by the respondent's medical history (previous myocardial infarction [MI], stroke, peripheral arterial disease [PAD]; history of malignancies [treated or otherwise]); plans to migrate outside their community within the next 5 years; pregnancy, breastfeeding or lactation in women, and those who are eligible but at home only once a month which would make them unavailable for follow-up. A detailed description on how the participants were randomly selected was discussed in a previous paper. ${ }^{11,12}$ Informed consent was obtained in all participants.

\section{Data Collection}

Face-to-face interview was done at the participant's residence. Socio-demographic data such as age, highest educational attainment and employment status were obtained during the interview. They were also asked regarding their smoking history. On a separate day, participants were asked to go to a barangay hall or a health center for the physical examination. They were advised to fast for 10-12 hours prior to the medical examination. Anthropometric measurements (i.e., height, weight and waist circumference) were all measured using standardized techniques. Participants were asked to remove their shoes, heavy outer garments and hair ornaments prior to the measurement procedures. Height was measured using a stadiometer (microtoise), which was taped vertically to a hard flat wall surface with the base at floor level. The weight was measured using a Detecto weighing scale (Missouri, USA) that was calibrated at the beginning and end of each examination day. The scale was balanced with both sliding weights at zero and the balance bar aligned. Participants were instructed to stand at the center of the platform with weight distributed evenly to both feet. Waist circumference (WC) was measured using a tape measure at a level midway between the lower rib margin and iliac crest with the tape all around the body in horizontal position.

Blood pressure was measured using an automated device (Omron Model IA2, which has been validated for use among Filipinos) after at least 5 minutes of rest in the sitting position, using a cuff properly adapted to the arm size. The average of three blood pressure measurements was taken. A trained and registered medical technologist drew blood samples. Blood samples for fasting blood glucose (FBG), total cholesterol (TC), triglyceride (TG), low density lipoprotein cholesterol (LDL-C) and high density lipoprotein cholesterol (HDL-C) determination were stored in an ice box and sent to the Medical Research Laboratory of the Philippine General Hospital. Biochemical tests were done using a Cobas Mira blood analyzer (Roche Diagnostics, USA)

\section{Operational Definition}

The classification of urban and rural area of residence was based from the Philippine National Statistical Coordination Board (NSCB). An urban area was defined as having a population density of at least 1,000 persons per square kilometer or a central district population of at least 500 persons per square kilometer where the occupation of most of its inhabitants is non-farming or fishing. Its network of streets is in either parallel or in a right angle direction. Furthermore there must be at least 6 commercial, manufacturing or recreational establishments and at least three of the following: a) a town hall, church or chapel with religious service at least once a month, b) a public plaza, park or cemetery, c) a market place or building where trading activities are done at least once a week, d) a public building like a school, hospital, health center and library. Any area that does not meet the following classification is classified as rural. ${ }^{13}$

Body mass index (BMI) is a ratio of weight in kilograms over the square of the height in meters that is used to classify weight in adults. Two (BMI) classifications were used: a) the Who Health Organization (WHO) classification: underweight $<18.5$, ideal $18.5-24.9$, overweight $25-29.9$ and obese $\geq 30$, and b) the Asia Pacific classification: underweight $<18.5$, ideal $18.5-22.9,23-24.9$ overweight and $>25$ obese. ${ }^{14}$ Based on WHO, abdominal obesity by waist circumference (WC) is defined as $>102 \mathrm{cms}$ (40 in) in males and $>88 \mathrm{cms}$ (35 in) in females, while waist:hip ratio (WHR) 
is $\geq 0.9$ in males and $\geq 0.85$ in females. ${ }^{15}$ Hypertension classification is based on the JNC 7 report. Prehypertension is defined as a systolic blood pressure (SBP) of 120-129 $\mathrm{mmHg}$ or a diastolic blood pressure (DBP) of $80-89 \mathrm{mmHg}$. Stage 1 hypertension is a SBP of $140-159 \mathrm{mmHg}$ or a DBP of 90- $99 \mathrm{mmHg}$. Stage 2 hypertension is a SBP $\geq 160 \mathrm{mmHg}$ or a DBP of $\geq 100$ mmHg. ${ }^{16}$ Fasting blood glucose (FBG) classification was based on the American Diabetes Association (ADA) 2008 report, in which serum FBG of 5.6$6.9 \mathrm{mmol} / \mathrm{L}$ is diagnosed as impaired fasting glucose (prediabetes) and FBG $\geq 7 \mathrm{mmol} / \mathrm{L}$ is diagnosed as diabetes, with no caloric intake for at least 8 hours. ${ }^{17}$ Cut-off values for the lipid profile were adopted from the National Cholesterol Education Program Adult Treatment Panel 3 (NCEP ATP III) report. Dyslipidemia was defined as having one of the following: high TC, high TG, high LDL-C and/ or low HDL$\mathrm{C}$, non-HDL-C which were $\geq 6.2 \mathrm{mmol} / \mathrm{L}, \geq 2.26 \mathrm{mmol} / \mathrm{L}, \geq$ $4.1 \mathrm{mmol} / \mathrm{L}, \geq 4.1$ and $\leq 1.03 \mathrm{mmol} / \mathrm{L}$, respectively. ${ }^{18}$

\section{Statistical Method}

Descriptive statistics such as mean, standard deviation (SD), and median were computed for continuous variables while frequency and percentages were presented for categorical variables. The Mann-Whitney U-test was applied to examine the statistical significance of each clinical risk factor by sex (Male vs. Female). All statistical analyses were performed using Stata 10 for Windows ${ }^{\circledR}$ (STATACORP LP1, College Station, Texas, USA). A statistical significance was set at $p<0.05$.

\section{Results}

A total of 3,072 eligible participants were recruited, composed of $43 \%$ male and $57 \%$ female. Males had a higher median SBP, DBP, FBG and TG with a low median HDL compared to females. Females had a higher median LDL and BMI compared to males. There was almost similar median TC for both sexes (Table 1). However, in spite of these differences, the prevalence of diabetes, high TC and a high LDL-C were similar for both sexes (Table 2) Overall prevalence of diabetes mellitus was at $5 \%$. The prevalence of smokers in the overall population was high (34.6\%). More females (9 out of 10) than males (1 out of 3 ) denied having smoked. Overall prevalence of overweight in the cohort was $23.7 \%$ by WHO classification and $16.7 \%$ by the Asia Pacific classification. Meanwhile the overall prevalence of obesity was $6.84 \%$ by WHO and $30.6 \%$ by the Asia Pacific classification. Females were more obese than males using either criterion. Overall prevalence of those with hypertension was $14.5 \%$ of which two-thirds were at the stage 1 level. There were more hypertensive males than females. Nearly half (43\%) of the males and a quarter $(26 \%)$ of the females were in the pre-hypertensive level. Dyslipidemia, defined by a low HDL or a high TG, was seen to be higher in males. Low HDL (38\%) was the most common lipid abnormality. (Table 2) There is a positive relationship of the prevalence of risk factors with age (except for smoking) as seen in both sexes (Table 3).

Table 1. Cardiovascular Risk Factors According to Sex

\begin{tabular}{|c|c|c|c|c|}
\hline & $\begin{array}{c}\text { Total } \\
(\mathrm{n}=3,072)\end{array}$ & $\begin{array}{c}\text { Male } \\
(n=1,329)\end{array}$ & $\begin{array}{c}\text { Female } \\
(n=1,743)\end{array}$ & $p$-value \\
\hline \multicolumn{5}{|l|}{ Systolic BP } \\
\hline Mean (SD) & $121.28(18.48)$ & 126.19 (17.38) & $117.53(18.43)$ & $<0.0001$ \\
\hline Median & 118.33 & 124 & 114 & \\
\hline \multicolumn{5}{|l|}{ Diastolic BP } \\
\hline Mean (SD) & $72.45(12.01)$ & $73.32(12.44$ & 71.78 (11.63) & 0.0003 \\
\hline Median & 70.67 & 71.67 & 70 & \\
\hline \multicolumn{5}{|l|}{ Fasting Blood } \\
\hline \multicolumn{5}{|l|}{ Glucose } \\
\hline Mean (SD) & $5.42(1.58)$ & $5.50(1.49)$ & $5.37(1.65)$ & $<0.0001$ \\
\hline Median & 5.14 & 5.24 & 5.06 & \\
\hline \multicolumn{5}{|l|}{ Total cholesterol } \\
\hline Mean (SD) & $4.77(1.09)$ & $4.76(1.15)$ & $4.78(1.04)$ & 0.333 \\
\hline Median & 4.68 & 4.68 & 4.69 & \\
\hline \multicolumn{5}{|l|}{ Triglyceride } \\
\hline Mean (SD) & $1.44(0.88)$ & $1.70(1.05)$ & $1.24(0.65)$ & $<0.0001$ \\
\hline Median & 1.22 & 1.46 & 1.07 & \\
\hline \multicolumn{5}{|l|}{ HDL cholesterol } \\
\hline Mean (SD) & $1.16(0.34)$ & $1.09(0.32)$ & $1.22(0.35)$ & $<0.0001$ \\
\hline Median & 1.12 & 1.04 & 1.18 & \\
\hline \multicolumn{5}{|l|}{ LDL cholesterol } \\
\hline Mean (SD) & $2.94(0.95)$ & $2.89(0.96)$ & $2.98(0.95)$ & 0.0017 \\
\hline Median & 2.89 & 2.82 & 2.94 & \\
\hline \multicolumn{5}{|l|}{ Body Mass Index } \\
\hline Mean (SD) & $23.35(4.28)$ & $23.12(3.94)$ & $23.53(4.51)$ & 0.055 \\
\hline Median & 22.73 & 22.56 & 22.84 & \\
\hline
\end{tabular}

*Mann-Whitney U-test

\section{Rural and urban}

There were more overweight, obese, higher level (stage 2) of hypertension and pre-diabetic participants living in the urban areas. Rural dwellers tend to have more smokers, low HDL-C, high TC and high non-HDL-C. Dyslipidemia by high LDL-C and high TG were similar for both areas. Somewhat similar proportions of diabetics were seen in either area of residence. (Table 4)

\section{Employment and Educational status}

Those who were employed have more risk factors such as smoking, overweight, obesity by the Asia-Pacific criteria, hypertension, impaired fasting glucose and dyslipidemia (Table 5). Participants who have attained a college level of education were more overweight, obese and have a higher TC, LDL-C and TG levels. More smokers, hypertensive, diabetics and low HDL-C were seen in those participants who have reached at least a primary level of education (Table 6). 
Table 2. Prevalence of Cardiovascular Risk Factors According to Sex

\begin{tabular}{|c|c|c|c|}
\hline & $\begin{array}{c}\text { Male } \\
(\mathrm{n}=1,329) \\
\%\end{array}$ & $\begin{array}{c}\text { Female } \\
(\mathrm{n}=1,743) \\
\%\end{array}$ & $\begin{array}{c}\text { Total } \\
(\mathrm{n}=3,072) \\
\%\end{array}$ \\
\hline \multicolumn{4}{|l|}{ Age (years) } \\
\hline $20-29$ & 30.25 & 26.33 & 28.03 \\
\hline $30-39$ & 35.89 & 35.86 & 35.87 \\
\hline $40-50$ & 33.86 & 37.81 & 36.10 \\
\hline \multicolumn{4}{|l|}{ Smoking History } \\
\hline Current smoker & 53.57 & 7.86 & 27.64 \\
\hline Previous smoker & 12.49 & 2.81 & 7.00 \\
\hline Non-smoker & 33.94 & 89.33 & 65.36 \\
\hline \multicolumn{4}{|l|}{ Body Mass Index (WHO) } \\
\hline$(<18.5)$ Underweight & 9.78 & 9.70 & 9.73 \\
\hline (18.5 - 24.9) Ideal & 61.32 & 58.46 & 59.70 \\
\hline (25 - 29.9) Overweight & 23.48 & 23.92 & 23.73 \\
\hline$(\geq 30)$ Obese & 5.42 & 7.92 & 6.84 \\
\hline \multicolumn{4}{|l|}{ Body Mass Index (Asia Pacific) } \\
\hline (<18.5) Underweight & 9.78 & 9.70 & 9.73 \\
\hline$(18.5-22.9)$ Normal & 44.32 & 42.00 & 43.00 \\
\hline (23 - 24.9) Overweight & 17.01 & 16.47 & 16.70 \\
\hline$(\geq 25)$ Obese & 28.89 & 31.84 & 30.57 \\
\hline \multicolumn{4}{|l|}{ Blood Pressure } \\
\hline Normotensive & 40.11 & 63.35 & 53.29 \\
\hline Prehypertensive & 42.81 & 25.90 & 33.22 \\
\hline Stage 1 hypertension & 11.89 & 6.78 & 8.99 \\
\hline Stage 2 hypertension & 5.19 & 3.96 & 4.50 \\
\hline \multicolumn{4}{|l|}{ Total Cholesterol (mmol/L) } \\
\hline$<5.2$ & 69.50 & 69.19 & 69.34 \\
\hline $5.2-6.1$ & 20.92 & 21.51 & 21.26 \\
\hline$\geq 6.2$ & 9.56 & 9.29 & 9.41 \\
\hline \multicolumn{4}{|l|}{ LDL cholesterol (mmol/L) } \\
\hline$<2.6$ & 40.63 & 35.80 & 37.89 \\
\hline $2.6-3.3$ & 33.33 & 33.56 & 33.46 \\
\hline $3.4-4$ & 15.65 & 19.85 & 18.03 \\
\hline$\geq 4.1$ & 10.38 & 10.79 & 10.61 \\
\hline \multicolumn{4}{|l|}{ HDL cholesterol (mmol/L) } \\
\hline$<1.03$ & 47.63 & 31.04 & 38.22 \\
\hline $1.03-1.54$ & 45.37 & 53.82 & 50.16 \\
\hline$\geq 1.55$ & 7.00 & 15.15 & 11.62 \\
\hline \multicolumn{4}{|l|}{ Triglycerides (mg/dL) } \\
\hline$<1.7$ & 62.23 & 82.10 & 73.50 \\
\hline $1.7-2.25$ & 18.28 & 10.73 & 14.00 \\
\hline$\geq 2.26$ & 19.49 & 7.17 & 12.50 \\
\hline \multicolumn{4}{|l|}{ Non - HDL Cholesterol } \\
\hline$<3.4$ & 43.49 & 47.45 & 45.74 \\
\hline $3.4-4$ & 25.66 & 25.53 & 25.59 \\
\hline$\geq 4.1$ & 30.85 & 27.02 & 28.68 \\
\hline \multicolumn{4}{|l|}{ Fasting Blood Glucose (mmol/L) } \\
\hline$<5.5$ & 63.60 & 72.95 & 68.90 \\
\hline $5.5-6.9$ & 31.50 & 21.94 & 26.08 \\
\hline$\geq 7$ & 4.90 & 5.11 & 5.02 \\
\hline
\end{tabular}

Table 3. Comparison of Cardiovascular Risk Factors According to Sex and Age Group

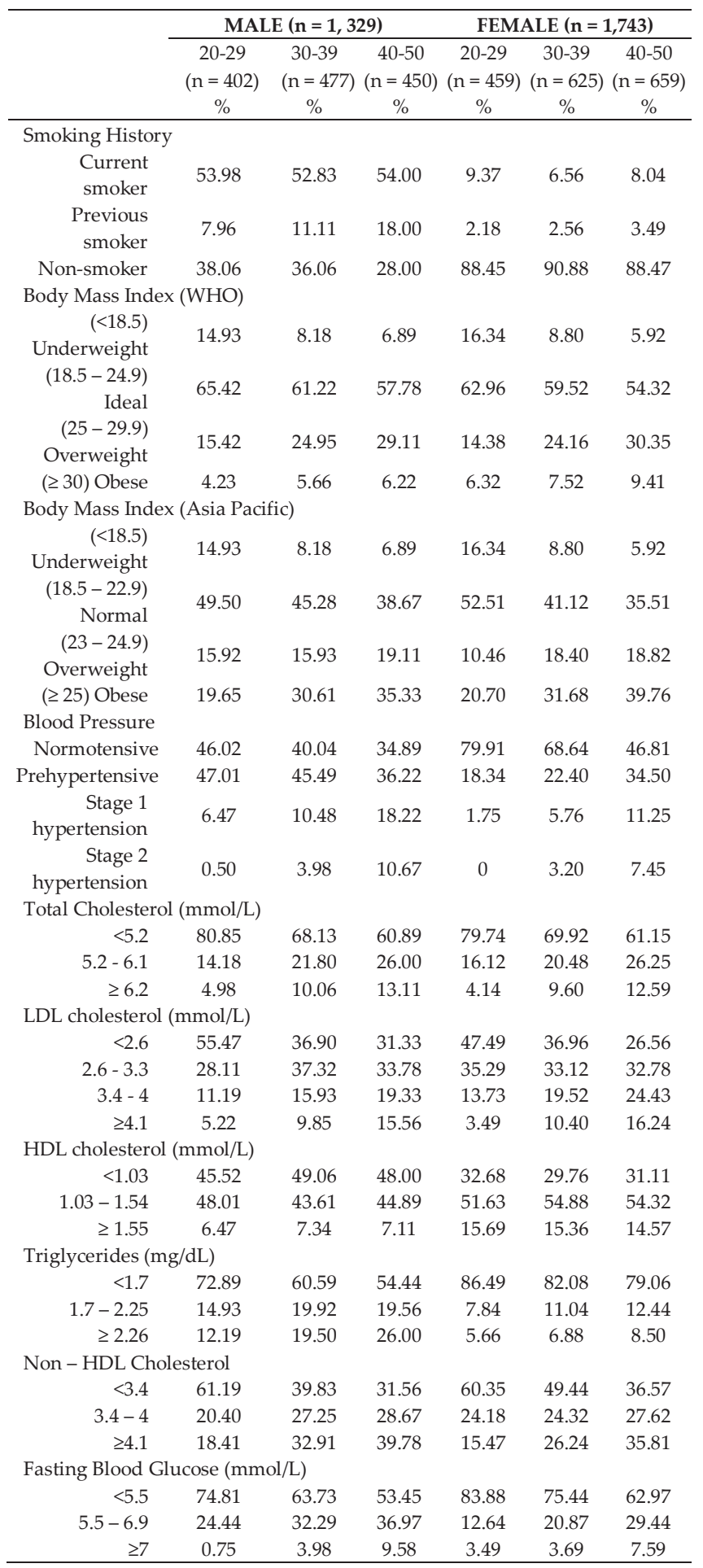


LIFECARE: “Cardiovascular Risk Profile"

Table 4. Prevalence of Cardiovascular Risk Factors According to Place of Residence

\begin{tabular}{|c|c|c|c|}
\hline & $\begin{array}{c}\text { Urban } \\
(\mathrm{n}=817) \\
\%\end{array}$ & $\begin{array}{c}\text { Rural } \\
(\mathrm{n}=2,255) \\
\%\end{array}$ & $\begin{array}{c}\text { Total } \\
(\mathrm{n}=3,072) \\
\% \\
\end{array}$ \\
\hline \multicolumn{4}{|l|}{ Smoking History } \\
\hline Current smoker & 25.95 & 28.25 & 27.64 \\
\hline Previous smoker & 7.22 & 6.92 & 7.00 \\
\hline Non-smoker & 66.83 & 64.83 & 65.36 \\
\hline \multicolumn{4}{|l|}{ Body Mass Index (WHO) } \\
\hline$(<18.5)$ Underweight & 9.18 & 9.93 & 9.73 \\
\hline$(18.5-24.9)$ Ideal & 55.57 & 61.20 & 59.70 \\
\hline (25 - 29.9) Overweight & 25.95 & 22.93 & 23.73 \\
\hline$(\geq 30)$ Obese & 9.30 & 5.94 & 6.84 \\
\hline \multicolumn{4}{|l|}{ Body Mass Index (Asia Pacific) } \\
\hline$(<18.5)$ Underweight & 9.18 & 9.93 & 9.73 \\
\hline$(18.5-22.9)$ Normal & 36.96 & 45.19 & 43.00 \\
\hline (23-24.9) Overweight & 18.60 & 16.01 & 16.70 \\
\hline$(\geq 25)$ Obese & 35.25 & 28.87 & 30.57 \\
\hline \multicolumn{4}{|l|}{ Blood Pressure } \\
\hline Normotensive & 51.29 & 54.02 & 53.29 \\
\hline Prehypertensive & 34.15 & 32.89 & 33.22 \\
\hline Stage 1 hypertension & 8.57 & 9.14 & 8.99 \\
\hline Stage 2 hypertension & 6.00 & 3.95 & 4.50 \\
\hline \multicolumn{4}{|l|}{ Total Cholesterol (mmol/L) } \\
\hline$<5.2$ & 72.58 & 68.16 & 69.34 \\
\hline $5.2-6.1$ & 18.85 & 22.13 & 21.26 \\
\hline$\geq 6.2$ & 8.57 & 9.71 & 9.41 \\
\hline \multicolumn{4}{|l|}{ LDL cholesterol (mmol/L) } \\
\hline$<2.6$ & 37.09 & 38.18 & 37.89 \\
\hline $2.6-3.3$ & 32.93 & 33.66 & 33.46 \\
\hline $3.4-4$ & 18.85 & 17.74 & 18.03 \\
\hline$\geq 4.1$ & 11.14 & 10.42 & 10.61 \\
\hline \multicolumn{4}{|l|}{ HDL cholesterol (mmol/L) } \\
\hline$<1.03$ & 33.29 & 40.00 & 38.22 \\
\hline $1.03-1.54$ & 53.98 & 48.78 & 50.16 \\
\hline$\geq 1.55$ & 12.73 & 11.22 & 11.62 \\
\hline \multicolumn{4}{|l|}{ Triglycerides (mg/dL) } \\
\hline$<1.7$ & 73.68 & 73.44 & 73.50 \\
\hline $1.7-2.25$ & 13.95 & 14.01 & 14.00 \\
\hline$\geq 2.26$ & 12.36 & 12.55 & 12.50 \\
\hline \multicolumn{4}{|l|}{ Non - HDL Cholesterol } \\
\hline$<3.4$ & 50.06 & 44.17 & 45.74 \\
\hline $3.4-4$ & 25.09 & 25.76 & 25.59 \\
\hline$\geq 4.1$ & 24.85 & 30.07 & 28.68 \\
\hline \multicolumn{4}{|l|}{ Fasting Blood Glucose (mmol/L) } \\
\hline$<5.5$ & 65.61 & 70.10 & 68.90 \\
\hline $5.5-6.9$ & 28.89 & 25.06 & 26.08 \\
\hline$\geq 7$ & 5.51 & 4.84 & 5.02 \\
\hline
\end{tabular}

Table 5. Prevalence of Cardiovascular Risk Factors According to Employment Status

\begin{tabular}{|c|c|c|c|}
\hline & $\begin{array}{c}\text { Employed } \\
(\mathrm{n}=2,068) \\
\%\end{array}$ & $\begin{array}{c}\text { Unemployed } \\
(\mathrm{n}=1,004) \\
\%\end{array}$ & $\begin{array}{c}\text { Total } \\
(\mathrm{n}=3,072) \\
\%\end{array}$ \\
\hline \multicolumn{4}{|l|}{ Age (years) } \\
\hline $20-29$ & 23.26 & 37.85 & 28.03 \\
\hline $30-39$ & 38.39 & 30.68 & 35.87 \\
\hline $40-50$ & 38.35 & 31.47 & 36.10 \\
\hline \multicolumn{4}{|l|}{ Smoking History } \\
\hline Current smoker & 33.27 & 16.04 & 27.64 \\
\hline Previous smoker & 8.27 & 4.38 & 7.00 \\
\hline Non-smoker & 58.46 & 79.58 & 65.36 \\
\hline \multicolumn{4}{|l|}{ Body Mass Index (WHO) } \\
\hline$(<18.5)$ Underweight & 8.46 & 12.35 & 9.73 \\
\hline (18.5 - 24.9) Ideal & 59.57 & 59.96 & 59.70 \\
\hline (25-29.9) Overweight & 25.15 & 20.82 & 23.73 \\
\hline$(\geq 30)$ Obese & 6.82 & 6.87 & 6.84 \\
\hline \multicolumn{4}{|l|}{ Body Mass Index (Asia Pacific) } \\
\hline$(<18.5)$ Underweight & 8.46 & 12.35 & 9.73 \\
\hline$(18.5-22.9)$ Normal & 41.92 & 45.22 & 43.00 \\
\hline (23-24.9) Overweight & 17.65 & 14.74 & 16.70 \\
\hline$(\geq 25)$ Obese & 31.96 & 27.69 & 30.57 \\
\hline \multicolumn{4}{|l|}{ Blood Pressure } \\
\hline Normotensive & 49.15 & 61.81 & 53.29 \\
\hline Prehypertensive & 36.43 & 26.62 & 33.22 \\
\hline Stage 1 hypertension & 9.97 & 6.98 & 8.99 \\
\hline Stage 2 hypertension & 4.45 & 4.59 & 4.50 \\
\hline \multicolumn{4}{|l|}{ Total Cholesterol (mmol/L) } \\
\hline$<5.2$ & 67.94 & 72.21 & 69.34 \\
\hline $5.2-6.1$ & 21.81 & 20.12 & 21.26 \\
\hline$\geq 6.2$ & 10.25 & 7.67 & 9.41 \\
\hline \multicolumn{4}{|l|}{ LDL cholesterol (mmol/L) } \\
\hline$<2.6$ & 36.90 & 39.94 & 37.89 \\
\hline $2.6-3.3$ & 33.46 & 33.47 & 33.46 \\
\hline $3.4-4$ & 17.94 & 18.23 & 18.03 \\
\hline$\geq 4.1$ & 11.70 & 8.37 & 10.61 \\
\hline \multicolumn{4}{|l|}{ HDL cholesterol (mmol/L) } \\
\hline$<1.03$ & 38.93 & 36.75 & 38.22 \\
\hline $1.03-1.54$ & 49.85 & 50.80 & 50.16 \\
\hline$\geq 1.55$ & 11.22 & 12.45 & 11.62 \\
\hline \multicolumn{4}{|l|}{ Triglycerides (mg/dL) } \\
\hline$<1.7$ & 70.70 & 79.28 & 73.50 \\
\hline $1.7-2.25$ & 14.94 & 12.05 & 14.00 \\
\hline$\geq 2.26$ & 14.36 & 8.67 & 12.50 \\
\hline \multicolumn{4}{|l|}{ Non - HDL Cholesterol } \\
\hline$<3.4$ & 43.04 & 51.29 & 45.74 \\
\hline $3.4-4$ & 27.08 & 22.51 & 25.59 \\
\hline$\geq 4.1$ & 29.88 & 26.20 & 28.68 \\
\hline \multicolumn{4}{|l|}{ Fasting Blood Glucose (mmol/L) } \\
\hline$<5.5$ & 66.88 & 73.08 & 68.90 \\
\hline $5.5-6.9$ & 27.99 & 22.13 & 26.08 \\
\hline$\geq 7$ & 5.13 & 4.79 & 5.02 \\
\hline
\end{tabular}


Table 6. Prevalence of Cardiovascular Risk Factors According to Educational Attainment

\begin{tabular}{|c|c|c|c|}
\hline & $\begin{array}{c}\text { Elementary } \\
(n=615) \\
\%\end{array}$ & $\begin{array}{c}\text { High school } \\
(\mathrm{n}=1,650) \\
\%\end{array}$ & $\begin{array}{c}\text { College } \\
(\mathrm{n}=800) \\
\%\end{array}$ \\
\hline \multicolumn{4}{|l|}{ Smoking History } \\
\hline Current smoker & 36.42 & 27.09 & 21.88 \\
\hline Previous smoker & 6.34 & 7.58 & 6.25 \\
\hline Non-smoker & 57.24 & 65.33 & 71.88 \\
\hline \multicolumn{4}{|l|}{ Body Mass Index (WHO) } \\
\hline$(<18.5)$ Underweight & 10.41 & 10.24 & 8.00 \\
\hline$(18.5-24.9)$ Ideal & 64.72 & 59.45 & 56.25 \\
\hline (25 - 29.9) Overweight & 19.67 & 24.30 & 25.87 \\
\hline$(\geq 30)$ Obese & 5.20 & 6.00 & 9.88 \\
\hline \multicolumn{4}{|l|}{ Body Mass Index (Asia Pacific) } \\
\hline (<18.5) Underweight & 10.41 & 10.24 & 8.00 \\
\hline$(18.5-22.9)$ Normal & 47.48 & 43.33 & 38.63 \\
\hline (23-24.9) Overweight & 17.24 & 16.12 & 17.63 \\
\hline$(\geq 25)$ Obese & 24.88 & 30.30 & 35.75 \\
\hline \multicolumn{4}{|l|}{ Blood Pressure } \\
\hline Normotensive & 49.27 & 54.18 & 54.13 \\
\hline Prehypertensive & 35.77 & 32.79 & 32.25 \\
\hline Stage 1 hypertension & 9.43 & 8.85 & 9.00 \\
\hline Stage 2 hypertension & 5.37 & 4.12 & 4.63 \\
\hline \multicolumn{4}{|l|}{ Total Cholesterol (mmol/L) } \\
\hline$<5.2$ & 68.46 & 69.94 & 68.50 \\
\hline $5.2-6.1$ & 23.09 & 20.48 & 21.63 \\
\hline$\geq 6.2$ & 8.46 & 9.58 & 9.88 \\
\hline \multicolumn{4}{|l|}{ LDL cholesterol (mmol/L) } \\
\hline$<2.6$ & 38.86 & 37.58 & 37.75 \\
\hline $2.6-3.3$ & 31.38 & 34.06 & 33.63 \\
\hline $3.4-4$ & 19.51 & 18.24 & 16.63 \\
\hline$\geq 4.1$ & 10.24 & 10.12 & 12.00 \\
\hline \multicolumn{4}{|l|}{ HDL cholesterol (mmol/L) } \\
\hline$<1.03$ & 41.30 & 39.21 & 33.75 \\
\hline $1.03-1.54$ & 47.80 & 50.36 & 51.50 \\
\hline$\geq 1.55$ & 10.89 & 10.42 & 14.75 \\
\hline \multicolumn{4}{|l|}{ Triglycerides (mg/dL) } \\
\hline$<1.7$ & 74.15 & 74.42 & 70.88 \\
\hline $1.7-2.25$ & 13.66 & 13.15 & 16.13 \\
\hline$\geq 2.26$ & 12.20 & 12.42 & 13.00 \\
\hline \multicolumn{4}{|l|}{ Non - HDL Cholesterol } \\
\hline$<3.4$ & 44.55 & 45.82 & 46.38 \\
\hline $3.4-4$ & 26.18 & 25.64 & 24.88 \\
\hline$\geq 4.1$ & 29.27 & 28.55 & 28.75 \\
\hline \multicolumn{4}{|l|}{ Fasting Blood Glucose (mmol/L) } \\
\hline$<5.5$ & 65.20 & 68.73 & 71.50 \\
\hline $5.5-6.9$ & 29.43 & 26.42 & 22.88 \\
\hline$\geq 7$ & 5.37 & 4.67 & 5.50 \\
\hline
\end{tabular}

The Philippine LIFECARE cohort is the first longitudinal study in this country that will look into the epidemiology of CVD. We included adults whose age range comprised mostly the workforce of our society. Individuals with known CVD were excluded since this study will later on look into all possible trajectories of development of the disease. The baseline data on prevalence of cardiovascular risk factors is common among this group. In contrast with the available national data, the NNHeS, showed a higher overall prevalence of smoking, hypertension and obesity but with less diabetes. ${ }^{5}$ However, these two cohorts were incomparable since the NNHeS also included older individuals aged over 50 years old.
Our results showed that there were more males who have more cardiovascular risk factors compared to females. The widening gap in the frequency of risk factors between sexes maybe due to behavioural and psychosocial factors seen in men by which they are less adaptive to stressful events. ${ }^{19}$ Another reason could be attributed to the hormonal state of women brought about by estrogen. Estrogen is a protective hormone to women in the reproductive state that affects the process of atherosclerosis through various mechanisms. Estrogens have been reported to have a lowering effect on TC and LDL by upregulating the LDL receptor, ${ }^{20}$ increase levels of $\mathrm{HDL}^{21,22,23}$ and also have an acute vasodilatory effect on the vessel wall with inhibition of smooth muscle proliferation which may retard the process of hypertension. ${ }^{24}$ However, contrary to these mechanisms the TC and LDL-C were similar for both sexes with more borderline high LDL-C levels in females. There were more females who were obese, which is also consistent with the NNHes data. This finding might be that females are more sedentary and tend to engage less in exercise..$^{25,26}$

Effects of these risk factors to our cardiovascular system takes sometime to fully manifest into a disease. This is why we see a more cardiovascular risk factors and events as age increases. Age is considered to be a non-modifiable risk factor for CVD. In fact age is an independent risk factor used in scoring system for predicting cardiovascular events. ${ }^{27,28}$

Based on location, those living in the urban areas appear to be fatter and hypertensive with impaired fasting glucose, while those in the rural areas have more lipid abnormalities and are smokers. Risk factor variations among the different areas may be due to a difference in lifestyle. The livelihood in rural areas is mostly agriculture. Farmers consume more energy-rich foods to make it to their hard day of labor and also smoke to relieve some of their stress. In contrast, urban dwellers eat more energy-rich foods but with less energy expenditure due to their sedentary lifestyle. However, in other countries it has been seen that urbanization poses more risk for CVD due to increasing rate of obesity, hypertension, dyslipidemia and diabetes. ${ }^{29}$

Our findings of more risk factors seen in those who were employed could be due to stress from work and probably the financial capacity to support their vices and eat an unhealthy diet. However, in previous studies it has been shown that stress from work or also known as job strain was not associated with hypertension, ${ }^{30}$ obesity, ${ }^{31}$ and dyslipidemia, ${ }^{30,32}$ but only to smoking ${ }^{33}$ and diabetes..$^{30}$

Similar findings of an inverse relation between level of education and blood pressure $34,35,36$ and smoking 37,38 was seen in this cohort as reported in earlier reports. The probable reasons could be that the more educated participants seek earlier treatment, have awareness of the ill effects of hypertension and smoking, or, as seen in one of our articles, the preference for salty food by those with lower education attainment. This cohort showed that prevalence of obesity, 
overweight and hyperlipidemia increased in those who have at least reached a college level of education. This is in contrary to other studies that showed inverse relationship between these risk factors and level of education. ${ }^{39,40}$

Awareness of unhealthy eating practices could be the key reason to this finding. It is not a common practice for most Filipinos to look at food labels for caloric content. Disseminating information to promote the importance of food labels and encouraging all Filipinos on how to prepare and eat healthy meals and live a healthy lifestyle should be part of strategies to re-educate the public.

\section{Conclusion}

Older participants, males and those who were employed tend have more cardiovascular risk factors. Urban dwellers were more hypertensive, overweight, obese and with impaired fasting glucose. More smokers and dyslipidemia by high TC, high non-HDL-C and low HDL-C were seen in those living in the rural areas. Participants who have at least reached a college level of education were more overweight, obese and have dyslipidemia by a high TC, TG and LDL-C while there were more smokers, low HDL-C and hypertensive participants who have reached a lower level of education. Therefore, health policies focused on this group should be implemented to alleviate the looming rise of CVD in our country.

\section{Acknowledgments}

The following organizations provided financial assistance to the project: Pfizer Asia, Pfizer International, Pfizer Philippines, Department of Health (Philippines), Philippine Council for Health and Research Development, Diabetes Philippines, Philippine Society of Hypertension, and the Philippine Lipid and Atherosclerosis Society. The University of the Philippines Manila through the College of Medicine and the National Institutes of Health's Institute of Clinical Epidemiology have also supported the project. We also wish to thank our support team (Rona May de Vera, Alma Amparo and Rachel Longalong), all our field interviewers and barangay health workers who helped us in this study. Lastly, we thank Dr. Marilette Falagne for helping us writing this manuscript.

\section{References}

1. Department of Health, Leading Causes of Mortality [Online]. 2013 [cited 2013 April]. Available from http://www.doh.gov.ph/node/198.html.

2. Dzau VJ, Antman EM, Black HR, et al. The cardiovascular disease continuum validated: clinical evidence of improved patient outcomes: Part I: Pathophysiology and Clinical Trial Evidence (Risk factors through stable coronary artery disease). Circulation. 2006; 114:2850-70.

3. Sy RG, Dans AL, Punzalan FER, Amarillo ML, Velandria F. for the FNRI-HDL Study Group. The prevalence of dyspidemia, hypertension, stroke and angina pectoris in the Philippines Phillip J Intern Med. 2003; 41:1-6.
4. Morales DD, Punzalan FE, Paz-Pacheco E, Sy RG, Duante CA. National Nutrition and Health Survey: 2003 Group. Metabolic Syndrome in the Philippine general population: prevalence and risk for atherosclerotic cardiovascular disease and diabetes mellitus. Diab Vasc Dis Res. 2008; 5(1):36-43.

5. Sy RG, Morales DD, Dans AL, et al. Prevalence of atherosclerosis related risk factors and diseases in the Philippines. J Epidemiol. 2012; 22(5):440-7.

6. Jacobsen BK, Thelle DS. Risk factors for coronary heart disease and level of education. The Troms V. Heart Study. Am J Epidemiol. 1988; 127(5):923-32.

7. Matthews KA, Kelsey SF, Meilahn EN, Kuller LH, Wing RR. Educational attainment and behavioral and biologic risk factors for coronary heart disease in middle aged women. Am J Epidemiol. 1989; 129:1132-44.

8. Greiser E, Joeckel KH, Giersiepen K, et al. Cardiovascular disease risk factors, CHD morbidity and mortality in the Federal Republic of Germany. Int J Epidemiol. 1989; 18(suppl 1):S118-24.

9. Salonen JT. Socioeconomic status and risk of cancer, cerebral stroke and death due to coronary heart disease and any disease: a longitudinal study in eastern Finland. J Epidemiol Commun H. 1982; 36:194-197.

10. Pekkanen J, Tuomilehto J, Uutela A, Vartiainen E, Nissinen A. Social class, health behavior, and mortality among men and women in Eastern Finland. BMJ. 1995; 311(7005):589-93.

11. Castillo-Carandang NT, Sison OT, Grefal ML, et al. A community-based validation study of the Short-Form 36 Version 2 Philippines (Tagalog) in two cities in the Philippines. PLoS ONE. 2013; 8(12): e83794.

12. Sy RG, Llanes EJ, Reganit PF, et al. Socio-demographic factors and the prevalence of metabolic syndrome among Filipinos from the LIFECARE cohort. J Atheroscler Thromb, 2014; 21 Suppl 1:S9-17.

13. Concepts and Definitions, Urban/Rural Classification, 1997-2014, Philippine Statistics Authority-National Statistics Coordination Board. [Online] Available from http://www.nscb.gov.ph/activestats/psgc/ articles/con_urbanrural.asp.

14. $\mathrm{WHO} / \mathrm{IASO} / \mathrm{IOTF}$. The Asia perspective: redefining obesity and its treatment. ISBN 0-9577082-1-1. February 2000.

15. Waist circumference and waist-hip ratio: report of a WHO expert consultation. ISBN 9789241501491. December 2008.

16. Chobanian AV, Bakris GL, Black HR, et al. National Heart, Lung, and Blood Institute Joint National Committee on Prevention, Detection, Evaluation, and Treatment of High Blood Pressure; National High Blood Pressure Education Program Coordinating Committee. The seventh report of the Joint National Committee on Prevention, Detection, Evaluation, and Treatment of High Blood Pressure: the JNC 7 report. JAMA. 2003; 289(19):2560-72.

17. Standards of Medical Care in Diabetes. Diabetes Care Vol. 31 Suppl 1:S12-54, 2008.

18. Grundy S, Becker D, Clark L, et al. Third Report of the National Cholesterol Education Program (NCEP) Expert Panel on Detection, Evaluation and Treatment of High Blood Cholesterol in Adults (Adult Treatment Panel III) Final Report. Circulation.2002; 106(25):3143-3421.

19. Weidner G. Why do men get more heart disease than women? an international perspective. J Am Coll Health. 2000; 48(6):291-4.

20. Parini P, Angelin B, Rudling M. Importance of estrogen receptors in hepatic LDL receptor regulation. Arterioscler Thromb Vasc Biol.1997; 17(9):1800-5.

21. Herrington DM, Reboussin DM, Brosnihan KB, et al. Effects of estrogen replacement on the progression of coronary-artery atherosclerosis. N Engl J Med. 2000; 343(8):522-9.

22. Darj E, Crona N, Nilsson S. Effects on lipids and lipoproteins in women treated with oestradiol and progesterone. Maturitas. 1992; 15(3):209-15.

23. Effects of estrogen or estrogen / progestin regimens on heart disease risk factors in postmenopausal women. The Postmenopausal Estrogen / Progestin Interventions (PEPI) Trial. The Writing Group for the PEPI Trial. JAMA.1995; 273(3):199-208.

24. Mendelsohn ME, Karas RH. Estrogen and the blood vessel wall. Curr Opin Cardiol 1994; 9(5):619-26.

25. Eyler A, Wilcox S, Matson-Koffman D, et al. Correlates of physical activity among women from diverse/ racial/ ethnic groups. J Women's Health Gend Based Med. 2002; 11(3):239-53. 
26. Schuster PM, Waldron J. Gender differences in cardiac rehabilitation patients. Rehabil Nurs.1991;16(5):248-53.

27. Grundy SM, Pasternak R, Greenland P, Smith S Jr, Fuster V. Assessment of cardiovascular risk by use of multiple risk factor assessment equations: a statement for healthcare professionals from the AHA and ACC. Circulation.1999; 100(13):1481-92.

28. Conroy RM, Pyorala K, Fitzgerald AP, et al. Estimation of ten-year risk of fatal cardiovascular disease in Europe: the SCORE project. Eur Heart J. 2003; 24(11):987-1003.

29. Yusuf S, Reddy S, Ounpuu S, Anand S. Global burden of cardiovascular diseases: part i: general considerations, the epidemiologic transition, risk factors and impact of urbanization. Circulation. 2001; 104(22):2746-53.

30. Nyberg ST, Fransson EI, Heikkila K, et al. Job strain and cardiovascular disease risk factors: meta-analysis of individual-participant data from 47,000 men and women. PLoS One. 2013; 8(6): e67323.

31. Nyberg ST, Heikkila K, Fransson EI, et al. Job strain in relation to body mass index: pooled analysis of 160,000 adults from 13 cohort studies. J Intern Med. 2012; 272(1):65-73.

32. Soderberg M, Rosengren A, Hillstrom J, Lissner L, Toren K. A crosssectional study of the relationship between job demand-control, effort-reward imbalance and cardiovascular heart disease risk factors. BMC Public Health. 2012; 12:1102.

33. Heikkila K, Nyberg ST, Fransson EI, et al. Job strain and tobacco smoking: an individual-participant data meta-analysis of 166,130 adults in 15 European studies. PLoS One. 2012; 7(7): e35463. doi:10.1371/journal.pone.0035463.
34. Dyer AR, Stamler J, Shekelle RB, Schoenberger J. The relationship of education to blood pressure: findings on 40,000 employed Chicagoans. Circulation. 1976; 54(6):987-92.

35. Haglund BJ. Geographical and socioeconomic distribution of high blood pressure and borderline high blood pressure in a Swedish rural county. Scand J Soc Med. 1985; 13(2):53-66.

36. Stamler R, Shipley M, Elliot P, Dyer A, Sans S, Stamler J. Higher blood pressure in adults with less education some explanation from INTERSALT. Hypertension. 1992; 19(3):237-41.

37. Pierce JP, Fiore MC, Novotny TE, Hatziandreu EJ, Davis RM. Trends in cigarette smoking in the United States: educational differences are increasing. JAMA. 1989; 261(1):56-60.

38. Cavelaars AEJM, Kunst AE, Geurts JJ, et al. Educational differences in smoking: international comparison. BMJ. 2000; 320(7242):1102-7.

39. Millar WJ, Wigle DT. Socioeconomic disparities in risk factors for cardiovascular disease. CMAJ. 1986; 134(2):127-32.

40. Hoeymans N, Smit HA, Verkleij H, Kromhout D. Cardiovascular risk factors in relation to educational level in 36,000 men and women in the Netherlands. Eur Heart J. 1996; 17(4):518-25.

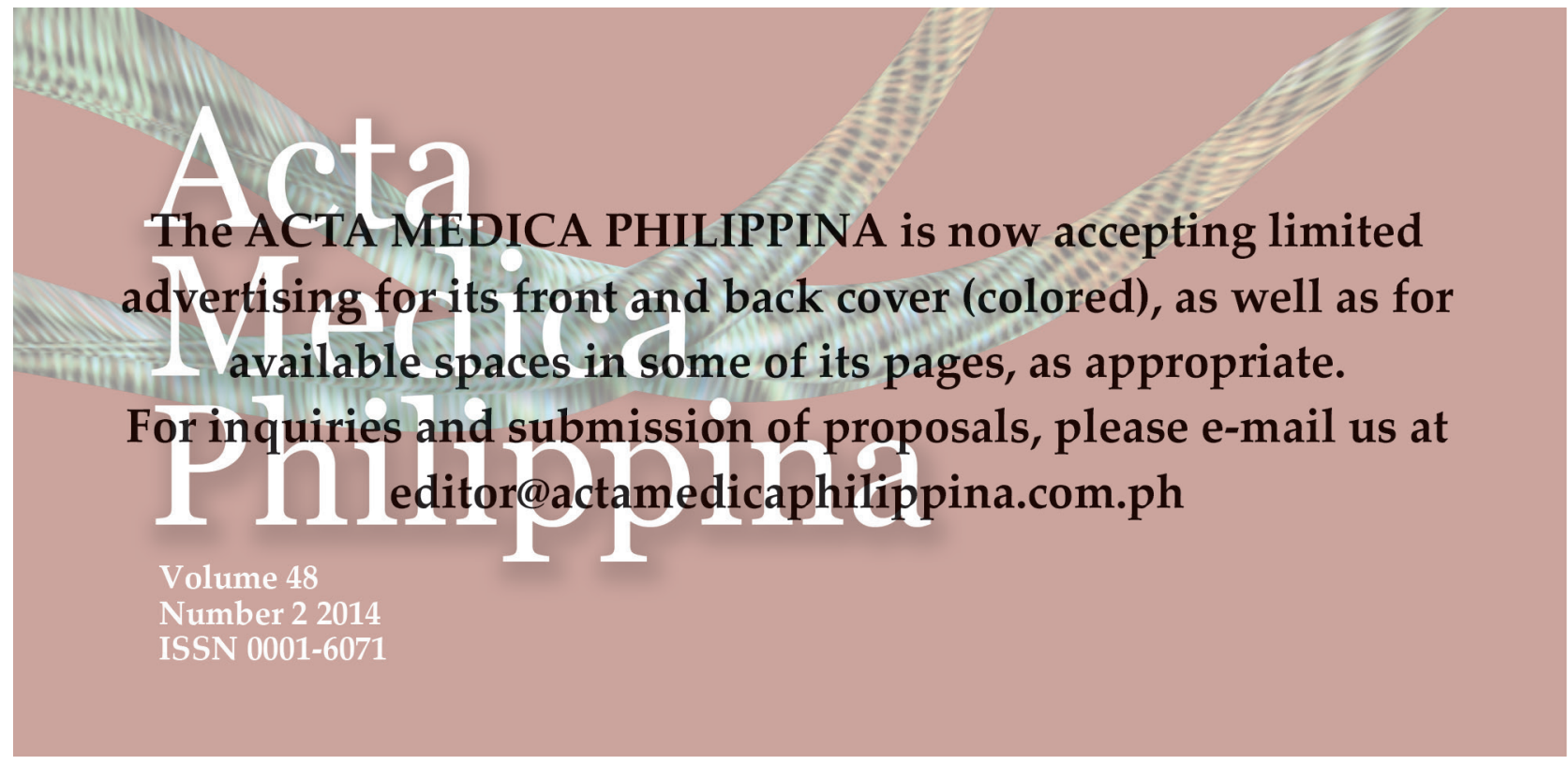

